\title{
A Validated HPLC Method for the Determination of Tiludronate Disodium on a Novel Brominated Stationary Phase
}

Wagdy $\mathrm{HA}^{1}$, Bowser $\mathrm{JE}^{2}$, Tarek $\mathrm{M}^{1}$ and Aboul-Enein $\mathrm{HY}^{3^{*}}$

${ }^{1}$ Pharmaceutical Analytical Chemistry Department, The British University in Egypt, Egypt

${ }^{2}$ Department of Clinical Sciences, College of Veterinary Medicine, Mississippi State University, Mississippi State, USA

${ }^{3}$ Pharmaceutical and Medicinal Chemistry Department, Pharmaceutical and Drug Industries Research Division, National Research Center (NRC), Dokki, Egypt

"Corresponding author: Aboul-Enein HY, Pharmaceutical and Medicinal Chemistry Department, Pharmaceutical and Drug Industries Research Division, National Research Center (NRC), Dokki, Giza 12522, Egypt, Tel: +201003678948; Fax: +20 3337093; E-mail: haboulenein@yahoo.com

Received date: October 27, 2016; Accepted date: November 29, 2016; Published date: November 30, 2016

Copyright: (C) 2016 Wagdy HA, et al. This is an open-access article distributed under the terms of the Creative Commons Attribution License, which permits unrestricted use, distribution, and reproduction in any medium, provided the original author and source are credited.

\begin{abstract}
An analytical method for analysis of Tiludronate; [4-chlorothiophenyl) methylene] bisphosphonate known as Tildren ${ }^{\circledR}$ is developed without pre or post derivatization on a newly introduced halogenated stationary phase namely pentabromobenzyl column (PBr column) for the first time.

The optimum HPLC conditions used are: A mobile phase composed of acetonitrile: Water: triethylamine: Acetic acid (50: 50: 0.05: 0.05; v: v: v: v), at a flow rate $0.5 \mathrm{~mL} / \mathrm{min}$, at temperature $35^{\circ} \mathrm{C}$. Two wavelengths were selected from the UV-spectrum namely 197 and $267 \mathrm{~nm}$.

The method is linear in the range of $0.06-0.6 \mathrm{mg} / \mathrm{mL}$ with square of the regression coefficient (r2) 0.9998 at 197 $\mathrm{nm}$. The limit of quantification (LOQ) is $0.040 \mathrm{mg} / \mathrm{mL}$ and the limit of detection (LOD) is $0.013 \mathrm{mg} / \mathrm{mL}$. The method is precise with \%RSD 0.41-1.36 (intra-day) and \%RSD 0.38-1.91 (inter-day). The method is found to be robust at temperature $35^{\circ} \mathrm{C} \pm 3^{\circ} \mathrm{C}$, wavelength $197 \mathrm{~nm} \pm 1 \mathrm{~nm}$, pH of the aqueous phase \pm 0.03 and $\% A C N 50 \% \pm 1 \%$.

At $267 \mathrm{~nm}$, the method is linear in the range of $0.08-0.8 \mathrm{mg} / \mathrm{mL}$ with $\mathrm{r} 20.9997$, LOQ is $0.050 \mathrm{mg} / \mathrm{mL}$ and LOD is $0.016 \mathrm{mg} / \mathrm{mL}$. The \%RSD for intra-day precision ranges from $0.96-1.74$, while for inter-day precision ranges from 1.09-2.32. The method is proved robust in temperature $35^{\circ} \mathrm{C} \pm 3^{\circ} \mathrm{C}$, wavelength $297 \mathrm{~nm} \pm 3 \mathrm{~nm}, \mathrm{pH}$ of the aqueous phase \pm 0.03 and $\% A C N 50 \% \pm 1 \%$.
\end{abstract}

The method is accurate with \% recovery ranged from $98.82-99.42 \%$ with \%RSD ranging from $0.210-1.023$.

This method is suitable for the assay of tiludronate in both bulk and in its veterinary pharmaceutical formulations.

Keywords: Tiludronate disodium; Halogenated stationary phases; Pentabromobenzyl group bonded (PBr) column; Veterinary pharmaceutical analysis; Non-nitrogen containing bisphosphonates

\section{Abbreviations:}

Ac: Acetic Acid; CAN: Acetonitrile; FDA: Food and Drug Administration; LOD: Limit of Detection; LOQ: Limit of Quantification; MeOH: Methanol; \%RSD: \% Relative Standard Deviation; PBr column: Pentabromobenzyl colum; TEA: Triethylamine

\section{Introduction}

Bisphosphonates are a class of drugs that act as inhibitors of bone resorption in humans [1]. The study of their action began in 1960 and they can be classified into Nitrogen-containing e.g., Neridronate, Alendronate, Pamidronate, Olpadronate, Risedronate, Zoledronate, Ibandronate or non-Nitrogen containing bisphosphonates e.g., Clodronate, Etidronate, Tiludronate [2].

Tiludronate; [4-chlorothiophenyl) methylene] bisphosphonate known as Tildren belongs to the non-Nitrogen-containing bisphosphonates (Figure 1) which is introduced in 2011 as veterinary medications for the treatment of horses [3]. The drug was approved by the Food and Drug Administration (FDA) in 2014 introduced in the United States markets [4].

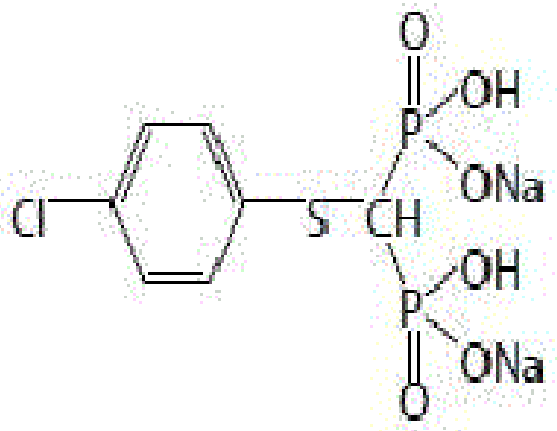

Figure 1: Structure of tiludronate disodium known as Tildren . 
It is used in the treatment of the clinical symptoms of navicular syndrome in horses. Navicular syndrome is caused by increases in mechanical stress on the navicular bone and leads to increase in osteoclastic activity, followed by disruption in normal bone remodeling those results in the process of bone lysis overcoming bone formation.

Tildren is administrated intravenously; it penetrates the osteoclasts by endocytosis resulting in decreasing the osteoclastic activity and ultimately decreasing bone resorption [5]. Lately tiludronate; due to its particular anti-inflammatory and analgesic properties, has also been used to treat other equine osteo-degenerative pathologies [6].

To date, few methods have been reported in literature for the analysis of Tildren" such as liquid chromatographic analysis using mass spectrometry by Wong et al. [3] and Popot et al. [1] and HPLC-UV for tiludronate by Fel et al. [7].

Pentabromobenzyl-bonded silica stationary phase known as Cosmosil $\mathrm{PBr}$ is a newly introduced halogenated stationary phase. The structure of this new phase is shown in Figure 2.

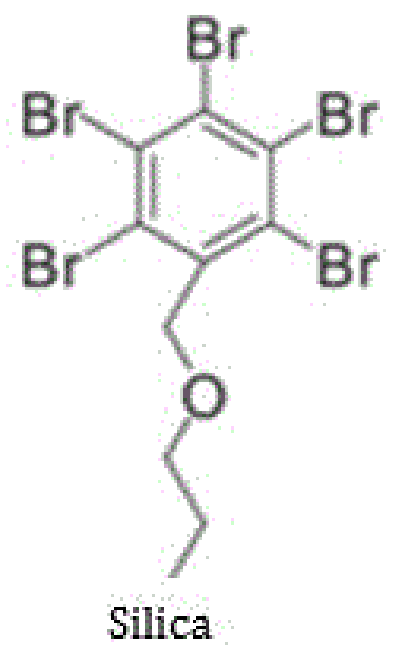

Figure 2: Structure of the stationary phase under investigation in this study named Cosmosil PBr.

The aim of this work is to develop a validated method for the direct analysis of Tildren, without pre- or post-derivatization on a newly halogenated stationary phase namely pentabromobenzyl column (Cosmosil PBr column). To the best of our knowledge, this is the first report describes the analysis of this drug on Cosmosil $\mathrm{PBr}$ column.

\section{Experimental Procedure}

\section{Equipment}

The analysis was performed on Thermo Fisher UHPLC Dionex Ultimate 3000. It consists of pump (ISO-3100SD), autosampler (WPS $3000 \mathrm{SL}$ ), column thermostat (TCC-3000 SD) and Diode Array Detector (DAD-3000 RS). The data acquisition is collected using Chromeleon 6.8 software.
The column used is Cosmosil $\mathrm{PBr}$, pentabromobrenzyl group bonded phase, $(150 \times 4.6 \mathrm{~mm}, 5 \mu \mathrm{m})$, purchased from Nacalai Tesque (Kyoto, Japan).

\section{Materials and reagents}

Methanol (MeOH) (HPLC grade), acetonitrile (ACN) (HPLC grade), triethylamine (TEA) and glacial Acetic acid (AC) were purchased from Sigma-Aldrich, Germany.

Tiludronate disodium and its veterinary formulation Tildren ${ }^{\circ}$ and were obtained from Ceva Santé Animale (Libourne, France).

\section{Methods}

For the standard stock solution $(0.1 \mathrm{mg} / \mathrm{mL})$ was prepared by dissolving $10 \mathrm{mg}$ in $100 \mathrm{~mL}$ deionized water.

Each Tildren vial contains $500 \mathrm{mg}$ tiludronic acid as tiludronate disodium and $250 \mathrm{mg}$ mannitol USP as excipient. For its assay, $10 \mathrm{mg}$ was dissolved into $100 \mathrm{~mL}$ deionized water. The solutions were kept at $5^{\circ} \mathrm{C}$ and covered with foils for weeks. The injection volume in all runs was $10 \mu \mathrm{L}$.

The optimum condition was achieved using mobile phase consisting of acetonitrile: Water: triethylamine (TEA): Acetic acid (AC) (50: 50: 0.0.5: 0.05; v: v: v: v), at a flow rate $0.5 \mathrm{~mL} / \mathrm{min}$, at temperature $35^{\circ} \mathrm{C}$. The mobile phase was filtrated using $0.45 \mu \mathrm{m}$ membrane filter, and then allowed to remain in ultrasonic bath for $30 \mathrm{~min}$. The UV detector was adjusted at wavelength $197 \mathrm{~nm}$ and $267 \mathrm{~nm}$.

The method validation was performed according ICH guidelines [8]. The parameters studied were linearity, Limit of Detection (LOD), Limit of Quantification (LOQ), precision (Inter- and Intra-day), accuracy and robustness. It is worth mentioning that the validation steps were performed at two wavelengths $197 \mathrm{~nm}$ and $267 \mathrm{~nm}$.

For linearity, 12 calibrations standards were prepared by serial dilution of tiludronate, covering a range of $0.06 \mathrm{mg} / \mathrm{mL}$ to $0.8 \mathrm{mg} / \mathrm{mL}$. Each of these 12 concentrations was injected 3 times. Then, a calibration curve was constructed by plotting the peak area against the corresponding concentrations $(\mathrm{mg} / \mathrm{mL})$ to study the linearity. Results were evaluated by calculating square of the regression coefficient (r2).

The Limit of Detection (LOD) is the lowest amount that can be detected. It was calculated from the calibration curve using this equation:

$$
\mathrm{LOD}=3.3(\sigma / \mathrm{S})
$$

LOQ is the lowest amount of analyte in a sample that can be quantitatively determined with suitable precision and accuracy. It was calculated from the calibration curve using this equation:

$$
\mathrm{LOQ}=10(\sigma / \mathrm{S})
$$

Where $\sigma$ is the standard deviation of the response and $\mathrm{S}$ is the slope of the calibration curve [8].

Precision is describing the degree of repeatability of an analytical method. In this work, the precision of the methods was evaluated in terms of inter- and intra-day precision. Both were expressed by calculating \% relative standard deviation (\%RSD) [9]. This was performed by analyzing 3 different concentrations $(0.08,0.1,0.2$ $\mathrm{mg} / \mathrm{mL})$ three times on the same day $(\mathrm{n}=9)$ : Intra-day precision (repeatability), for 3 different days: Inter-day precision. Each of these 3 
concentrations has been prepared three times and each was injected three times.

Accuracy is the closeness of the accepted value and the found value. Tildren $(0.1 \mathrm{mg} / \mathrm{mL})$ was spiked with known amount of standards 0.10 $\mathrm{mg} / \mathrm{mL}, 0.20 \mathrm{mg} / \mathrm{mL}$ and $0.30 \mathrm{mg} / \mathrm{mL}$, so that the final concentrations are $0.2 \mathrm{mg} / \mathrm{mL}, 0.3 \mathrm{mg} / \mathrm{mL}$ and $0.4 \mathrm{mg} / \mathrm{mL}$, respectively. Each sample was injected three times. The results were expressed as percentage recovery (\% recovery) and \%RSD [10]. For robustness, of the method, it was evaluated by the capacity of the method to remain uninfluenced by small changes in the experimental parameters [8].

\section{Results and Discussion}

\section{Method development}

Initially, the condition applied was water: $\mathrm{ACN}(50: 50 ; \mathrm{v}: \mathrm{v})$ at flow rate $0.7 \mathrm{~mL} / \mathrm{min}$ and temperature $25^{\circ} \mathrm{C}$, the tiludronate peak eluted early at $1.643 \mathrm{~min}$ as shown in Figure $3 \mathrm{~A}$. To increase the retention time, an increase in the percent aqueous phase was investigated, but it was observed that it led to peak split as shown in Figure 3B; this could be attributed to the high polarity of tiludronate. There is a competition between the aqueous phase mobile and tiludronate on the stationary phase. This split appeared even when the mobile phase composition was water: $\mathrm{ACN}(60: 40 ; \mathrm{v}$ : v).

Methanol was investigated as an alternative solvent based on the fact that it falls in a different part of the solvent selectivity triangle than CAN, and hence could create a dramatic change in analysis [11]. The mobile phase condition was water: $\mathrm{MeOH}(50: 50 ; \mathrm{v}$ : v) at flow rate 0.7 $\mathrm{mL} / \mathrm{min}$ and temperature $25^{\circ} \mathrm{C}$. The peak eluted slightly later in comparison to ACN (at tR $2.393 \mathrm{~min}$ ) however, the peak was broad as shown in Figure 3C. Accordingly, ACN was selected to be the organic solvent in this work.

Different conditions were then investigated to achieve optimum specifications for this HPLC method. As lowering the flow rate will increase tR, but broaden the peak, we decreased flow rate to 0.5 $\mathrm{mL} / \mathrm{min}$ accompanied by increase of the column temperature up to $35^{\circ} \mathrm{C}$, leading to enhanced peak shape.

Therefore, the condition: ACN: water (50: 50; v: v) at flow rate 0.5 $\mathrm{mL} / \mathrm{min}$ and temperature $35^{\circ} \mathrm{C}$ was investigated. The tiludronate peak appeared at $2.157 \mathrm{~min}$ (Figure 3D). Varying the conditions to: ACN: water: $\mathrm{AC}$ (50: 50: 0.05; v: v: v; $\mathrm{pH} 4.05$ ) at flow rate $0.5 \mathrm{~mL} / \mathrm{min}$ and temperature $35^{\circ} \mathrm{C}$ lead to a slight increase in $\mathrm{tR}(2.770 \mathrm{~min})$ (Figure 3E).

Ion-pair chromatography is a very common technique in analyzing polar organic compounds on RP-LC [2], and alteration in the mobile phase has been accomplished by adding Ac and TEA (0.05:0.05; v: v). Because of this, the following condition were applied using a mobile phase consisting of ACN: water: AC: TEA (50: 50: 0.05: 0.05; v: v: v: v; $\mathrm{pH} 5.09$ ) at flow rate $0.5 \mathrm{~mL} / \mathrm{min}$ and temperature $35^{\circ} \mathrm{C}$.

The tiludronate peak then eluted at $2.290 \mathrm{~min}$ (Figure 4A). It was observed that when the $\mathrm{pH}$ increased, the retention time (tR) slightly decreased. This can be attributed to the fact that at higher $\mathrm{pH}$ tiludronate becomes more ionized, and hence would elute earlier. The UV spectrum of tiludronate under the above-mentioned conditions was monitored. The optimal wavelengths were found to be $197 \mathrm{~nm}$ and $267 \mathrm{~nm}$ (Figure 4C).
Because our investigation found the condition ACN: water: AC: TEA (50: 50: 0.05: 0.05; v: v: v: v) at flow rate $0.5 \mathrm{~mL} / \mathrm{min}$ and temperature $35^{\circ} \mathrm{C}$ showed an optimum retention time and better peak shape in comparison to other conditions assessed, it was selected to be the optimum condition and the validation was accomplished under these specifications on both wavelengths (197 nm and $267 \mathrm{~nm}$ ).

The identified optimum condition for HPLC of Tildren on Cosmosil PBr column was investigated at two wavelengths: $197 \mathrm{~nm}$ (Figure 4A) and $267 \mathrm{~nm}$ (Figure 4B). At $197 \mathrm{~nm}$, it showed the highest sensitivity toward the analyte and at 267 lower sensitivity but the baseline was more stable, since it was above the cutoff of the mobile phase as shown in Figures $4 \mathrm{~A}$ and $4 \mathrm{~B}$ respectively.

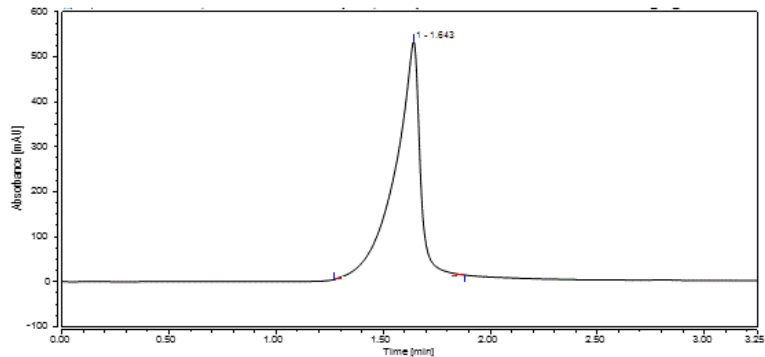

Figure 3A: Chromatograms of tiludronate disodium on $\mathrm{PBr}$ column showing different conditions: (A): Mobile phase ACN: Water (50: 50; v: v); flow rate $0.7 \mathrm{~mL} / \mathrm{min}, \mathrm{T}=25^{\circ} \mathrm{C}$.

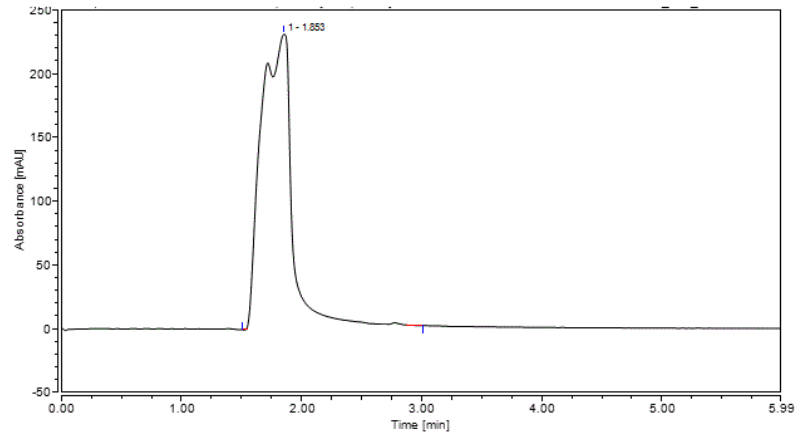

Figure 3B: Mobile phase ACN: Water (60: 40; v: v); flow rate 0.7 $\mathrm{mL} / \mathrm{min}, \mathrm{T}=25^{\circ} \mathrm{C}$.

Interaction between the analyte and the stationary phase can be explained from the following interactive forces: $\pi-\pi$ interactions between the pentabromobenzyl group on the stationary phase and the para-chlorophenyl group on the analyte. A competition between the two phosphonate groups and water content in the mobile phase on the stationary phase due to the formation of hydrogen bonding. This could explain the peak splitting associated with the higher percentage of the aqueous phase. London Dispersion force, a weak intermolecular force that results from dipoles temporarily induced from random unsymmetrical electron positions in two adjacent atoms, also known as "instantaneous dipole-induced dipole force". 
Citation: Wagdy HA, Bowser JE, Tarek M, Aboul-Enein HY (2016) A Validated HPLC Method for the Determination of Tiludronate Disodium on a Novel Brominated Stationary Phase. Pharm Anal Acta 7: 519. doi:10.4172/2153-2435.1000519

Page 4 of 6

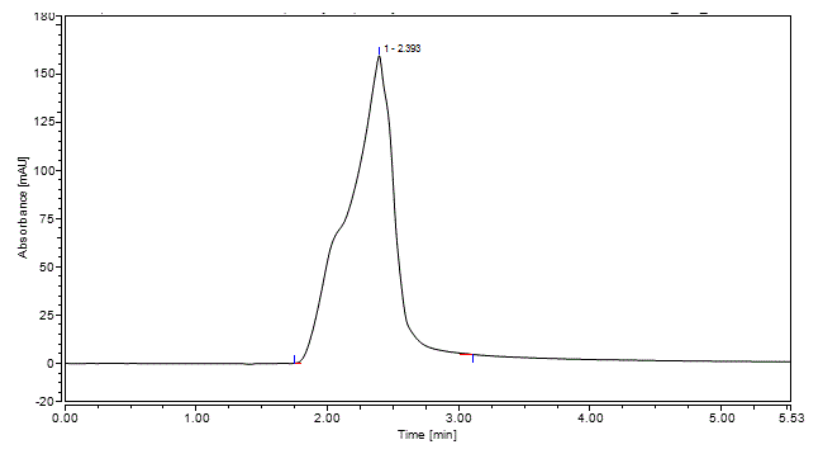

Figure 3C: Mobile phase $\mathrm{MeOH}$ : Water (50: 50; v: v); flow rate 0.7 $\mathrm{mL} / \mathrm{min}, \mathrm{T}=25^{\circ} \mathrm{C}$.

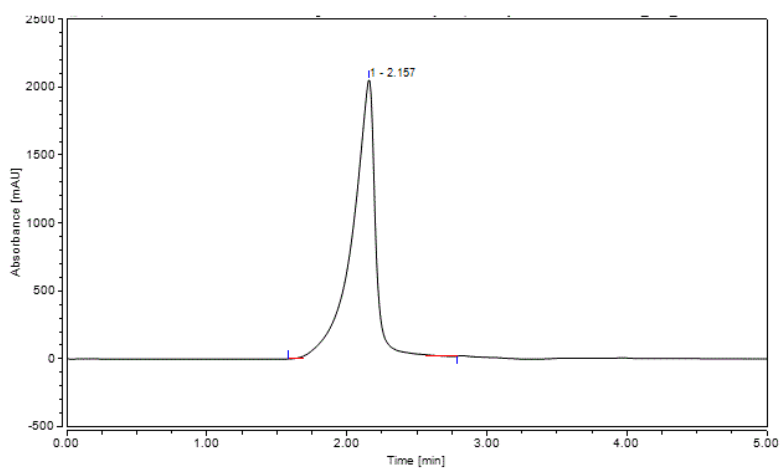

Figure 3D: Mobile phase ACN: Water (50: 50; v: v); flow rate 0.5 $\mathrm{mL} / \mathrm{min}, \mathrm{T}=35^{\circ} \mathrm{C}$.

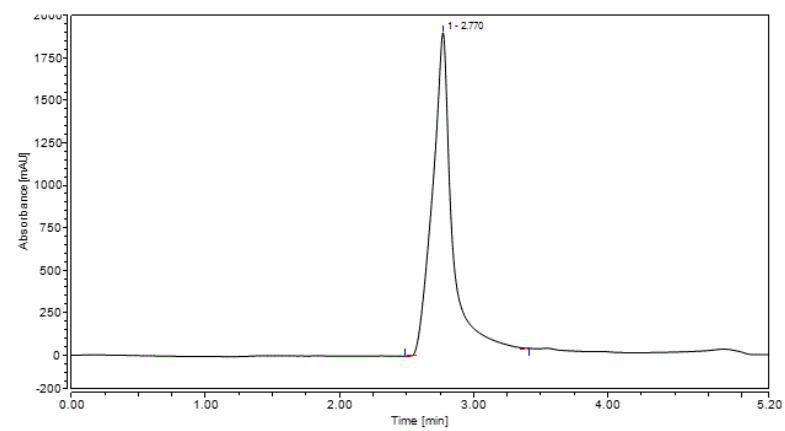

Figure 3E: Mobile phase ACN: Water: AC (50: 50: 0.05; v: v: v); flow rate $0.7 \mathrm{~mL} / \mathrm{min}, \mathrm{T}=25^{\circ} \mathrm{C}$.

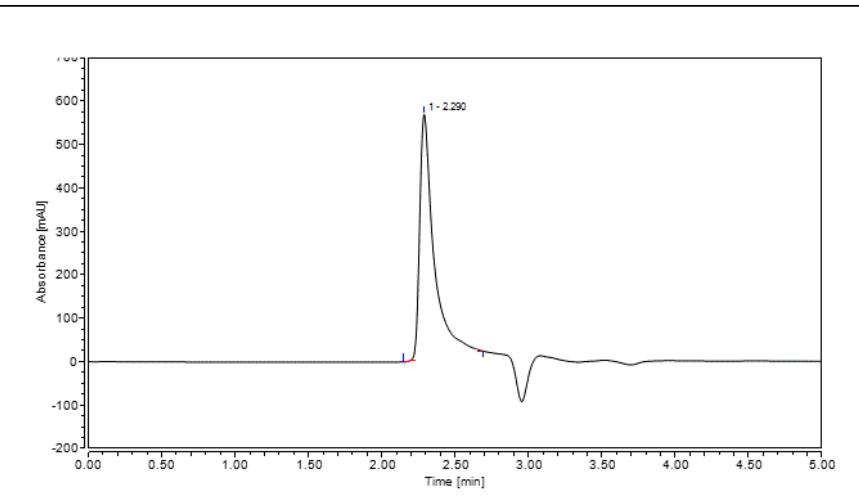

Figure 4A: Chromatograms of Tiludronate disodium on $\mathrm{PBr}$ column at optimum condition: Mobile phase ACN: Water: TEA: AC (50: 50: 0.05: 0.05 ; v: v: v: v); flow rate $0.5 \mathrm{~mL} / \mathrm{min}, \mathrm{T}=35^{\circ} \mathrm{C}$, $\mathrm{UV}=197 \mathrm{~nm}$, C: Mobile phase $\mathrm{MeOH}$ : Water (50: 50; v: v); flow rate $0.7 \mathrm{~mL} / \mathrm{min}, \mathrm{T}=25^{\circ} \mathrm{C}$.

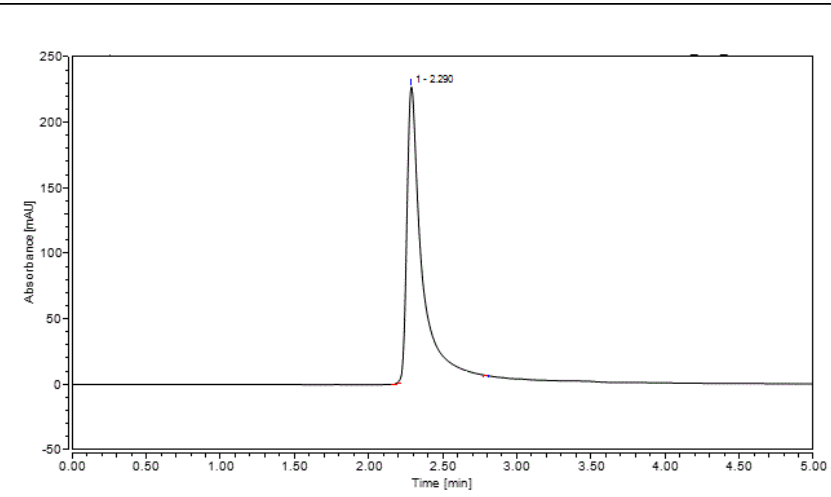

Figure 4A: Chromatograms of Tiludronate disodium on $\mathrm{PBr}$ column at optimum condition: Mobile phase ACN: Water: TEA: AC (50: 50: 0.05: 0.05; v: v: v: v); flow rate $0.5 \mathrm{~mL} / \mathrm{min}, \mathrm{T}=35^{\circ} \mathrm{C}$, $\mathrm{UV}=197 \mathrm{~nm}$.

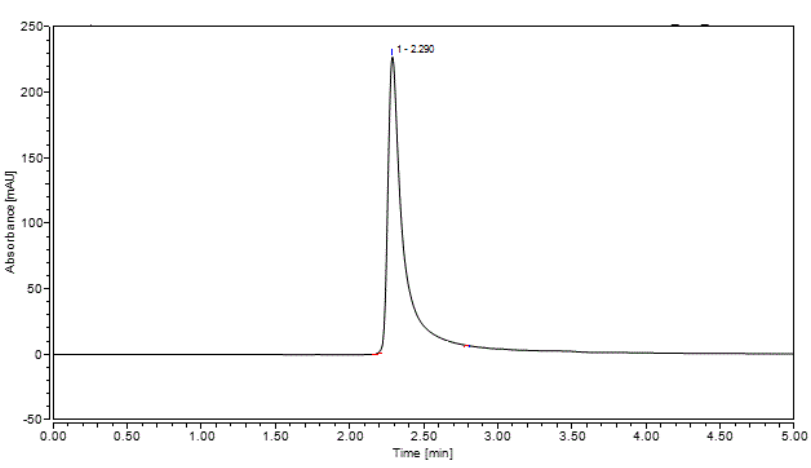

Figure 4B: Chromatograms of Tiludronate disodium on $\mathrm{PBr}$ column at optimum condition: Mobile phase ACN: Water: TEA: AC (50: 50: 0.05: 0.05; v: v: v: v); flow rate $0.5 \mathrm{~mL} / \mathrm{min}, \mathrm{T}=35^{\circ} \mathrm{C}, \mathrm{UV}=267 \mathrm{~nm}$. 
Citation: Wagdy HA, Bowser JE, Tarek M, Aboul-Enein HY (2016) A Validated HPLC Method for the Determination of Tiludronate Disodium on a

Page 5 of 6

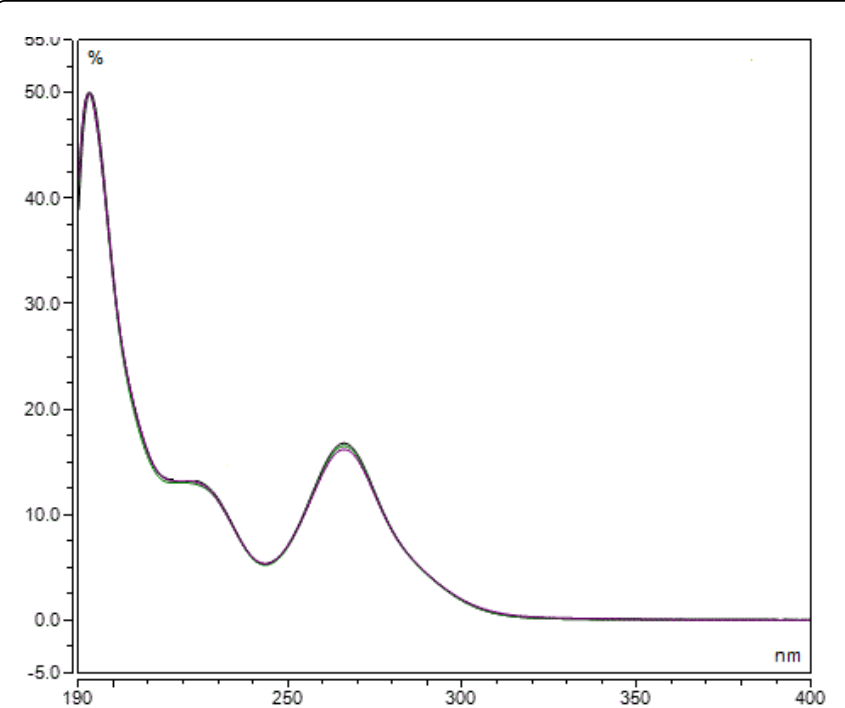

Figure 4C: Chromatograms of Tiludronate disodium on $\mathrm{PBr}$ column at optimum condition: Mobile phase ACN: Water: TEA: AC (50: 50: 0.05: 0.05; v: v: v: v); flow rate $0.5 \mathrm{~mL} / \mathrm{min}, \mathrm{T}=35^{\circ} \mathrm{C}$, UVSpectrum of Tildren. Mobile phase $\mathrm{MeOH}$ : Water (50: 50; v: v); flow rate $0.7 \mathrm{~mL} / \mathrm{min}, \mathrm{T}=25^{\circ} \mathrm{C}$.

\section{Method validation}

At $197 \mathrm{~nm}$, the calibration curve plotted for tiludronate was linear in the concentration range of $0.06 \mathrm{mg} / \mathrm{mL}$ to $0.6 \mathrm{mg} / \mathrm{mL}$. The regression equation for the calibration curve is $\mathrm{y}=622.13 \times-0.9841$. The square correlation coefficient $(\mathrm{r} 2)$ was found to be 0.9998 , which indicates good linearity of the method in this range. The limit of quantification (LOQ) and Limit of Detection (LOD) was found to be $0.040 \mathrm{mg} / \mathrm{mL}$ and $0.013 \mathrm{mg} / \mathrm{mL}$ respectively for standard drug solutions.

Intra-day precision was investigated by preparing three concentrations: $0.08,0.1$ and $0.2 \mathrm{mg} / \mathrm{mL}$; three times each; then each was injected three times and the \%RSD was $1.34,1.36$ and 0.41 , respectively.

The three previously mentioned concentrations were injected over 3 consecutive days to assess the inter-day precision and the \%RSD was $1.91,1.48$ and 0.38 , respectively, as shown in Table 1.

The robustness of the method was assessed by RSD values by carrying out small changes in the following parameters: Temperature, wavelengths and \%ACN and the results were as follow:

Temperature $35^{\circ} \mathrm{C} \pm 3{ }^{\circ} \mathrm{C}$ with $\%$ RSD $0.47 \%$.

Wavelength $197 \mathrm{~nm} \pm 1 \mathrm{~nm}$ with \%RSD 2.56\%.

$\%$ Acetonitrile $50 \% \pm 1 \%$ with $\%$ RSD $0.87 \%$.

$\mathrm{pH}$ of the aqueous phase \pm 0.03 with \%RSD $1.51 \%$.

While at $267 \mathrm{~nm}$, the calibration curve plotted for tiludronate was linear in the concentration range of $0.08 \mathrm{mg} / \mathrm{mL}$ to $0.8 \mathrm{mg} / \mathrm{mL}$. The regression equation for the calibration curve was $y=353.15 \times-3.9178$, the correlation coefficient $(\mathrm{r} 2)$ was 0.9997 , the LOQ was $0.051 \mathrm{mg} / \mathrm{mL}$ and the LOD was $0.016 \mathrm{mg} / \mathrm{mL}$ as shown in Table 1 .

\begin{tabular}{|l|l|l|l|l|}
\hline Parameters & \multicolumn{2}{|l|}{ Wavelength 197 nm } & \multicolumn{2}{l|}{ Wavelength 267 nm } \\
\hline $\begin{array}{l}\text { Regression } \\
\text { Equation, } \mathrm{r2}\end{array}$ & \multicolumn{2}{|l|}{$\mathrm{y}=622.13 \times-0.98410 .9998$} & $\mathrm{y}=353.15 \times-3.91780 .9997$ \\
\hline LOQ $(\mathrm{mg} / \mathrm{mL})$ & \multicolumn{2}{|l|}{0.04} & 0.051 & \multicolumn{2}{l|}{0.016} \\
\hline LOD $(\mathrm{mg} / \mathrm{mL})$ & 0.013 & $\begin{array}{l}\text { \%RSD } \\
\text { (Inter-day } \\
\text { precision) }\end{array}$ & $\begin{array}{l}\text { \%RSD } \\
\text { (Intra-day } \\
\text { precision) }\end{array}$ & $\begin{array}{l}\text { \%RSD (Inter- } \\
\text { day precision) }\end{array}$ \\
\hline Precision & day precision) & 1.91 & 1.69 & 2.32 \\
\hline $0.08 \mathrm{mg} / \mathrm{mL}$ & 1.34 & 1.48 & 1.74 & 2.11 \\
\hline $0.1 \mathrm{mg} / \mathrm{mL}$ & 1.36 & 0.38 & 0.96 & 1.09 \\
\hline $0.2 \mathrm{mg} / \mathrm{mL}$ & 0.41 & & & \\
\hline
\end{tabular}

Table 1: Validation parameters of Tildren ${ }^{\circ}$ using different wavelengths (197 $\mathrm{nm}$ and $267 \mathrm{~nm}$ ).

For intra-day precision, the \%RSD of the three concentrations: 0.08 , 0.1 and $0.2 \mathrm{mg} / \mathrm{mL}$ were $1.69,1.74$ and 0.96 respectively; while for inter-day precision, the \%RSD was 2.32, 2.11 and 1.09 .

For the robustness, the \%RSD for the following parameters was as follow:

Temperature $35^{\circ} \mathrm{C} \pm 3^{\circ} \mathrm{C}$ with \%RSD $0.48 \%$.

Wavelength $267 \mathrm{~nm} \pm 3 \mathrm{~nm}$ with \%RSD $2.13 \%$.

$\%$ Acetonitrile $50 \% \pm 1 \%$ with $\%$ RSD $1.39 \%$.

$\mathrm{pH}$ of the aqueous phase \pm 0.03 with $\% \mathrm{RSD} 1.93 \%$.

Similar results were obtained for accuracy using detection for both wavelengths. The \% recovery, as shown in Table 2, ranged from $98.82 \%$ to $99.42 \%$, and the \% RSD ranged from 0.21 to 1.02 .

\begin{tabular}{|l|l|l|l|l|}
\hline $\begin{array}{l}\text { Theoretical } \\
\text { concentration } \\
\mathbf{( m g / m L})\end{array}$ & $\begin{array}{l}\text { Actual } \\
\text { concentration*(m } \\
\mathbf{g} / \mathbf{m L})\end{array}$ & \%RSD & \%Recovery & \%RSD \\
\hline 0.2 & 0.198 & 0.982 & 99.42 & 1.023 \\
\hline 0.3 & 0.297 & 0.28 & 99.25 & 0.211 \\
\hline 0.4 & 0.395 & 0.67 & 98.82 & 0.53 \\
\hline *Average of 3 determinations & & & \\
\hline
\end{tabular}

*Average of 3 determinations

Table 2: Accuracy of Tildren .

\section{Application on preparation}

A $10 \mathrm{mg}$ Tildren of was dissolved into $100 \mathrm{~mL}$ deionized water. 10 $\mu \mathrm{L}$ was injected under the identified optimum condition on $\mathrm{PBr}$ column and tR was $2.307 \mathrm{~min}$, as presented in Figures 5A and 5B. 


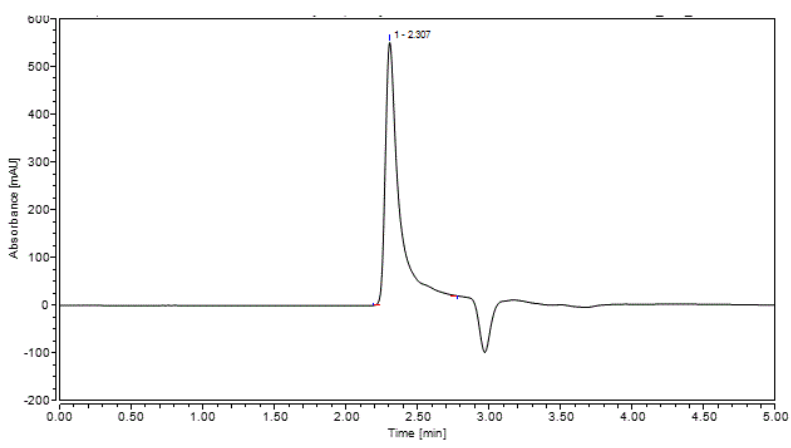

Figure 5A: Chromatograms of Tildren on $\mathrm{PBr}$ column at optimum condition: Mobile phase ACN: Water: TEA: AC (50: 50: 0.05: 0.05; $\mathrm{v}$ : v: v: v); flow rate $0.5 \mathrm{~mL} / \mathrm{min}, \mathrm{T}=35^{\circ} \mathrm{C}, \mathrm{UV}=197 \mathrm{~nm}$.

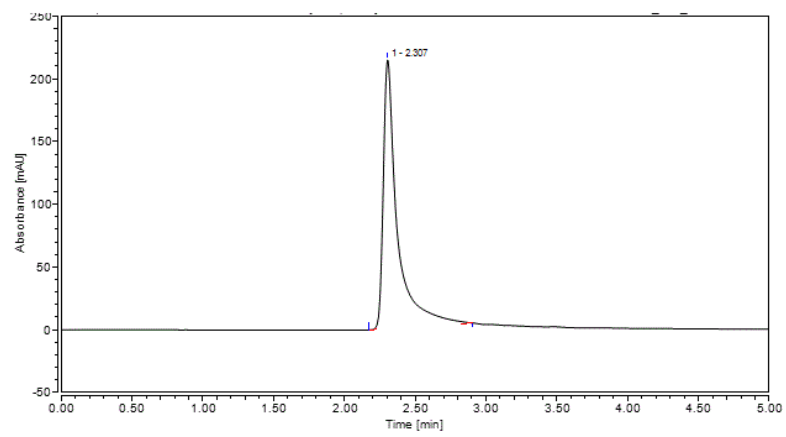

Figure 5B: Chromatograms of Tildren on $\mathrm{PBr}$ column at optimum condition: Mobile phase ACN: Water: TEA: AC (50: 50: 0.05: 0.05; v: v: v: v); flow rate $0.5 \mathrm{~mL} / \mathrm{min}, \mathrm{T}=35^{\circ} \mathrm{C}, \mathrm{UV}=267 \mathrm{~nm}$.

\section{Conclusion}

A method development for tiludronate disodium on $\mathrm{PBr}$ column without any prior- or post-derivatization on $\mathrm{PBr}$ column was described for the first time.

The optimum chromatographic condition was acetonitrile: Water: TEA: AC (50: 20: 0.05: 0.05; v: v: v: v), at a flow rate $0.5 \mathrm{~mL} / \mathrm{min}$, at temperature $35^{\circ} \mathrm{C}$. From the UV-spectrum, two optimum wavelengths were selected: 197 and $267 \mathrm{~nm}$. The interactive forces which are involved in the separation included $\pi-\pi$ interactions and hydrogen bonding.

The proposed method was validated according to $\mathrm{ICH}$ guidelines in terms of linearity, LOD, LOQ, precision (Inter- and Intra-day), accuracy and robustness.

At $197 \mathrm{~nm}$, the method was linear in the range of $0.06-0.6 \mathrm{mg} / \mathrm{mL}$ with $\mathrm{r} 20.9998$. The LOQ was $0.040 \mathrm{mg} / \mathrm{mL}$ and the LOD was 0.013 $\mathrm{mg} / \mathrm{mL}$. The $\% \mathrm{RSD}$ for intra-day precision ranged from 0.41-1.36, while for inter-day precision ranged from $0.38-1.91$. The method was found to be robust at temperatures $35^{\circ} \mathrm{C} \pm 3^{\circ} \mathrm{C}$, wavelength $197 \mathrm{~nm} \pm 1$ $\mathrm{nm}, \mathrm{pH}$ of the aqueous phase \pm 0.03 and $\% \mathrm{CAN}$ of $50 \% \pm 1 \%$.

At $267 \mathrm{~nm}$, the method was linear in the range of $0.08-0.8 \mathrm{mg} / \mathrm{mL}$ with $\mathrm{r} 2$ 0.9997. The LOQ was $0.050 \mathrm{mg} / \mathrm{mL}$ and the LOD was 0.016 $\mathrm{mg} / \mathrm{mL}$. The $\% \mathrm{RSD}$ for intra-day precision ranged from $0.96-1.74$, while for inter-day precision ranged from 1.09-2.32. The method was found to be robust at temperatures $35^{\circ} \mathrm{C} \pm 3^{\circ} \mathrm{C}$, wavelength $297 \mathrm{~nm} \pm 3$ $\mathrm{nm}, \mathrm{pH}$ of the aqueous phase \pm 0.03 and $\% \mathrm{CAN}$ of $50 \% \pm 1 \%$.

Accuracy of the \% recovery ranged from $98.82 \%$ - 99.42\% with \%RSD ranging from $0.210-1.023$.

The proposed method was applied on Tildren formulation and was found to be in good correlation with the standard. Accordingly, the proposed method was applicable for the analysis of tiludronate in bulk and preparation in less than $3 \mathrm{~min}$.

\section{Conflicts of Interest}

The authors declare no conflict of interest.

\section{References}

1. Popot MA, Garcia P, Hubert C, Bolopion A, Bailly-Chouriberry L (2014) HPLC/ESI-MSn method for non- amino bisphosphonate: Application to the detection of Tiludronate in equine plasma. J Chromatogr B 958: 108-116.

2. Zacharis CK, Tzanavaras PD (2008) Determination of bisphosphonate active pharmaceutical ingredients in pharmaceuticals and biological material: A review of analytical methods. J Pharmaceut Biomed 48: 483-496.

3. Wong AS, Ho EN, Wan TS, Lamb KK, Stewart BD (2015) Liquid chromatography-mass spectrometry analysis of five bisphosphonates in equine urine and plasma. J Chromatogr B 998: 1-7.

4. FDA (2014) FDA Provides Equine Veterinarians with Important Information about TILDREN and OSPHOS for Navicular Syndrome in Horses, U.S. Food \& Drug.

5. Tildren (2016) Mechanism of action of Tildren.

6. Solo SA, Barbare AC (2014) Bisphosphonates: Pharmacology and clinical approach to their use in equine osteoarticular diseases. J Equine Vet Sci 34: 727-737

7. Fels JP, Guyonnet J, Berger Y, Cautreels W (1988) Determination of (4Chlorophenyl) thiomethylene bisphosphonic acid, A new bisphosphonate, in biological fluids by high performance liquid chromatography. J Chromatogr Biomed 430: 73-79.

8. http://www.ich.org/fileadmin/Public_Web_Site/ICH_Products/ Guidelines/Quality/Q2_R1/Step4/Q2_R1_Guideline.pdf

9. Bartholomees U, Struyf T, Lauwers O, Ceunen S, Geuns JMC (2016) Validation of an HPLC method for direct measurement of steviol equivalents in foods. Food Chem 190: 270-275.

10. Wong YF, Makahleh A, Saad B, Ibrahim MN, Abdul Rahim A, et al. (2014) UPLC method for the determination of vitamin E homologues and derivatives in vegetable oils, margarines and supplement capsules using pentafluorophenyl column. Talanta 130: 299-306.

11. Snyder LR, Kirkland JJ, Glajch JL (1993) Practical HPLC Method Development (2nd edn.) John Wiley \& Sons, Inc., Wiley, New York. 